\title{
Social cost of tobacco-related disease and best buys
}

\author{
John M. Sanders \\ Centre for Health Advancement, NSW Department of Health \\ Email: jsand@doh.health.nsw.gov.au
}

A previous special issue of the Bulletin on tobacco control contained an article by David Collins and Helen Lapsley on the social costs of smoking in Australia. ${ }^{1}$ These same authors have undertaken a further research study for the NSW Department of Health to estimate the social costs of smoking in New South Wales (NSW) and the social benefits of reducing the prevalence of smoking in NSW. ${ }^{2}$

\section{Recent findings in social cost of tobacco for NSW}

For the financial year 1998-99, the social cost of tobacco use in NSW was estimated to be $\$ 6.6$ billion. This figure includes the tangible costs of tobacco use (such as net labour costs to the workforce and household, health care costs and resources used in tobacco consumption) and intangible costs. The estimated intangible social costs of tobacco use is $\$ 4.79$ billion, or $73 \%$ of total costs, and consists of loss of life resulting from the high level of premature mortality caused by smoking. The estimated direct health care cost is $\$ 476$ million, which includes costs in the medical (\$115 million), hospital (\$147 million), nursing home (\$147 million) and pharmaceutical (\$67 million) sectors.

Besides causing premature death in half of long-term smokers, there is a considerable cost to the health system. In 1998-99, there were 6860 deaths attributable to tobacco and 353180 hospital-bed days caused by tobacco-related illness. In addition, involuntary smoking was identified as being responsible for the deaths of 78 people: 35 of them aged under 15 or unborn babies.

\section{Recent findings in social benefit of tobacco for NSW}

The Collins and Lapsley study applied the most conservative method of estimation to determine the social benefits of reducing smoking prevalence in NSW. The study found that for the financial year 2001-02, the value of reducing prevalence by $5 \%$ over a 5 -year period was $\$ 2.36$ billion.
This represents $\$ 9046$ saved for each person prevented from smoking.

A separate report, commissioned by the Commonwealth Department of Health and Ageing, examined the benefitto-cost ratio of major public health programs in Australia. ${ }^{3}$ The authors found that an investment of $\$ 175$ million in tobacco control programs during the period 1971 to 2000 provided a net benefit $\$ 8.426$ billion during this same period. This translates to a benefit-to-cost ratio of $49: 1-$ a figure that compares very favourably with other public health programs. For example, programs to reduce coronary heart disease had a benefit-to-cost ratio of 11.5:1; HIV/AIDS prevention, 5.2:1; Haemophilis influenzae type B vaccination, 1.1:1; and road safety programs, $1.8: 1$.

The findings of these two reports provide evidence that indicates the benefit of anti-smoking programs. The figures describe a potential for large social benefits to be gained from effective anti-smoking programs and demonstrate that in comparison to many other public health programs, anti-smoking programs would yield very high rates of return.

Copies of Counting the costs of tobacco and the benefits of reducing smoking prevalence in $\mathrm{NSW}^{2}$ are available from the Better Health Centre Publications Warehouse (02) 98790443 or can be obtained from the NSW Health website: http://www.health.nsw.gov.au/ pubs/2005/smoking_reduction.html

\section{References}

1. Collins D, Lapsley H. The social cost of smoking in Australia. N S W Public Health Bull 2004; 15(5-6): 92-4.

2. Collins DJ, Lapsley HM. Counting the costs of tobacco and the benefits of reducing smoking prevalence in NSW. Sydney: NSW Department of Health, 2005.

3. Applied Economics. Returns on investment in public health: An epidemiological and economic analysis prepared for the Department of Health and Ageing. Canberra: Commonwealth Department of Health and Aged Care, 2003. 